\title{
Predictors of quality of life in a longitudinal study of users with severe mental disorders
}

\author{
Marie-Josée Fleury ${ }^{1,2^{*}}$, Guy Grenier², Jean-Marie Bamvita², Jacques Tremblay ${ }^{1}$, Norbert Schmitz ${ }^{1}$ and Jean Caron ${ }^{1}$
}

\begin{abstract}
Background: Since the end of the 20th century, quality of life has become a key outcome indicator in planning and evaluation of health services. From a sample of 297 users with severe mental disorders from Montreal (Canada), this study aimed to identify the key predictors of subjective quality of life (SQOL).

Methods: Users were recruited and interviewed from December 2008 to September 2010 and re-interviewed approximately 18 months later. A comprehensive framework including socio-demographic data, clinical, needs and functionality variables, negative life events, social support and healthcare service use, and appreciation data were considered as predictors. Clinical records and eight standardized instruments were used.

Results: Lower severity of needs, schizophrenia, better social integration, better reassurance of worth, fewer drug abuse problems, and living in supervised housing are predictors of SQOL. With regard to needs, absence or lower severity of needs in the areas of company, daytime activities, social exclusion, safety to self, and benefits are linked to SQOL.

Conclusion: Reducing the severity of needs is especially beneficial to ensure a higher SQOL for users with severe mental disorders. To improve SQOL, priority must be given to programs and interventions that promote the development of a stimulating and supportive social network, and maintain a plurality of residential services matching the functional abilities of users.
\end{abstract}

Keywords: Subjective quality of life, Needs, Social support, Severe mental disorders

\section{Background}

Since the end of the 20th century, quality of life (QOL) has become a key outcome indicator in planning and evaluation of health services in general [1-4], and primarily for chronic disorders, such as severe mental disorders, which require treatment over a long period [5]. The first mental health studies of QOL $[6,7]$ occurred at a time when it became necessary to expand community services for users discharged from psychiatric hospitals.

QOL has subjective and objective components. The subjective component refers to "well-being," "happiness" or "life satisfaction," whereas the objective component refers to aspects of environment and social functioning [2]. Several studies had shown discrepancies between subjective (SQOL) and objective QOL [6-11]. Most studies

\footnotetext{
* Correspondence: flemar@douglas.mcgill.ca

'Department of Psychiatry, McGill University, Douglas Mental Health University Institute, 6875 LaSalle Blvd., Montreal, Quebec H4H 1R3, Canada

${ }^{2}$ Douglas Hospital Research Centre, 6875 LaSalle Blvd., Montreal, Quebec H4H 1R3, Canada
}

focus on SQOL, which is influenced by multiple factors [12]. SQOL is closely linked to the recovery paradigm, which oriented most of the mental healthcare reforms in industrial countries $[13,14]$. For the health system, recovery is a goal to reach, and it is defined as "a way of living a satisfying, hopeful, and contributing life even with limitations caused by the illness. It involves the development of new meaning and purpose in one's life as one grows beyond the catastrophic effects of mental illness" [15].

Cross-sectional and comparative studies have identified several determinants of SQOL among users with severe mental disorders. Those studies found that SQOL is strongly associated with clinical variables $[3,4,16-20]$ and perceived needs [21-30]. Mood disorders are the most influential determinant of lower SQOL [16]. Regarding users with schizophrenia, a lower SQOL was associated with the presence of a second diagnosis such as major depression [3,4,17-20,31,32], and anxiety [4,18,19,33]. Users

\section{Biomed Central}

(c) 2013 Fleury et al.; licensee BioMed Central Ltd. This is an Open Access article distributed under the terms of the Creative Commons Attribution License (http://creativecommons.org/licenses/by/2.0), which permits unrestricted use, distribution, and reproduction in any medium, provided the original work is properly cited. 
with less severe psychiatric symptoms [1,34] and better cognitive performance [20] presented a higher SQOL. Meanwhile, past negative life events [17] produced a lower SQOL [32], especially among crime victims [3] and users with repeated suicide attempts.

Most studies have found a strong correlation between unmet needs (serious problems) and poorer SQOL [24,25,28-30]. A higher number of needs (met or unmet) is associated with a poorer SQOL [24,35]. Lower SQOL is most often associated with unmet social needs (intimate relationship, sexual expression, and especially company). Unmet basic and functioning needs are also associated with lower SQOL [25]. Other studies found an association with lower SQOL and unmet needs in daytime activities [24,26], childcare [24,30], psychological distress [26], accommodation, psychotic symptoms and benefits areas [30].

Relationships between SQOL and social support have also been the subject of several studies [36-38]. SQOL is significantly associated with the availability and adequacy of various social relationships [36], and social networks [10,37]. Among various components of social support, attachment and reassurance of worth have a significant link with SQOL [37]. Stigma and self-stigma are social variables negatively associated with SQOL $[39,40]$.

Socio-demographic variables are less strongly correlated with SQOL than clinical and need variables or social support $[2,19,41]$. However, SQOL is usually higher among users having a higher income [37] or a job [42,43]. Women show a higher SQOL than men [44]; the same is true for older versus younger users [45]. Quality of housing still has a crucial impact on SQOL [46-48]. According to the literature, autonomous accommodations are the best type of housing for users with severe mental disorders [47]. Supervised housing, however, is satisfactory for a substantial proportion of users [21,49,50].

The association between SQOL and use of mental health services is not as well covered in the literature. Antipsychotic medication compliance presents two opposing effects on SQOL. By reducing symptoms, medication increases SQOL; however, side effects are associated with a lower SQOL [22]. SQOL is also linked with greater satisfaction with mental healthcare [23].

Longitudinal analysis offers a stronger method than cross-sectional analyses for examining the relationship between SQOL and related variables [33]. Several longitudinal studies have investigated predictors of SQOL in users with severe mental disorders $[4,7,11,12,19,24-33,35,38,41,51-58]$, primarily schizophrenia $[11,19,24,28,31-33,35,38,41,52,54-58]$. Studies concerning perceived needs have found that quality of life improves when the number of serious needs decreases [24-26,29,30,38]. Other studies have noted that SQOL rises when symptom severity is reduced and functional ability is improved [11,12,24,28,33,35,41,54,56,58]. A reduction in stress-related factors [56] or in substance abuse [12] also improves SQOL. A stronger social network is also a significant predictor of a higher SQOL in these longitudinal studies [12,28,38]. Finally, some studies reported an improvement of SQOL among users with severe mental disorders after their discharge from hospital $[7,10]$. Other predictors of change in SQOL longitudinal studies are service use [12] and satisfaction with services $[4,58]$.

While some studies have longitudinally assessed the SQOL of users with severe mental disorders, most of them have gaps. First, in most longitudinal studies, the sample consists mainly or exclusively of users suffering from schizophrenia. Few studies have compared SQOL among a heterogeneous cohort of users with severe mental disorders living in the community. Second, studies investigating associations between perceived needs and SQOL have generally not included other factors in their analysis and, conversely, perceived needs were usually not considered in studies assessing clinical, socio-demographic, social support or service use as predictors of SQOL. Third, some variables (e.g. socio-demographic variables such as education or employment, negative life events) that could change SQOL are analyzed only in cross-sectional studies or not considered at all.

Based on a longitudinal study and a comprehensive conceptual framework, including variables less commonly studied in longitudinal research, this study aimed to determine 1) predictors of SQOL of a heterogeneous cohort of users with severe mental disorders over an 18-month period, and 2) areas of need that are the main predictors of the SQOL among this clientele living in the community. Based on the literature on the relationship between needs and SQOL, we hypothesized 1) that the severity of needs would be the strongest SQOL predictor for these users; and 2) that out of the needs categories, social needs would be the best predictor of higher or lower SQOL.

\section{Methods}

\section{Study design and users selection criteria}

This cohort study was conducted at a mental health university institute (MHUI - offering specialized services) and two health and social service centers (HSSC - offering primary mental healthcare), located in the southwestern area of Montreal, Canada. This urban area serves a population of 258,000 . The study involved a two-time measurement. Users with severe mental disorders were first randomly recruited at baseline, and then re-interviewed approximately 18 months later. They were aged from 18 to 65 years, diagnosed with a severe mental disorder according to the DSM-IV [59] diagnosis criteria 147 (schizophrenia and other psychotic disorders) 
or 161 (mood disorders). They resided in the zone covered by the study and received follow-up services at the MHUI or one of the two HSSC. They agreed to let the research team access their medical records and contact their case manager for the purpose of filling out a questionnaire on their functional ability in the community. Users with severe mental retardation, those following mandatory psychiatric treatment as determined by a judiciary board, and those with a history of hospitalization or emergency room visit in the three months prior to the initial interview were deemed unable to complete the questionnaire and were thus excluded from the study.

\section{Data collection}

User recruitment involved various strategies (posters for participant self-referral, recruitment at out-patient clinics, and information sessions or flyers to explain the project). Data was collected from December 2008 to September 2010 (baseline, T0), and from January 2011 to November 2011 (T1). Each user participated in two 90-minute interviews, conducted at a week's interval by a team of specially trained clinical professionals, and monitored by a research coordinator. Users' medical records were also reviewed. Interviews were based on eight questionnaires, seven of which were administered to users, and one (the Multnomah Community Ability Scale- MCAS) was completed by users' case managers (Table 1). Questionnaires were administered in English or French, according to the user's spoken language. With the exception of self-referral, users were contacted by their case managers who referred potential participants to the research team when appropriate. Each participant provided informed consent. The study protocol was approved by the MHUI and the two HSSC ethics review boards.

\section{Measurement instruments}

SQOL was measured with the modified version of the Satisfaction with Life Domains Scale (SLDS), initially developed by Baker and Intagliata [6], and translated in French and validated (Cronbach Alpha $=0.92$ ) by Caron et al. [60]. The SLSD assesses satisfaction regarding 20 life domains. Users had to choose among seven stylized faces ranging from 1 to 7 , from the happiest face (score 7) to the saddest one (score 1) that corresponded to their emotional state $[36,69,70]$. All item scores were added up to arrive at a total score. The psychometric properties of the SLDS are good, which makes it an effective instrument to measure SQOL. The SLDS is among the scales that were included in their entirety in the Wisconsin Quality of Life index, a multidimensional instrument containing 113 items [71,72].

The second major questionnaire used was the Montreal Assessment of Needs Questionnaire (MANQ), derived from the Camberwell Assessment of Need (CAN). The CAN is one of the most widely used instruments for needs assessment (Cronbach Alpha $=0.64$ for total needs) [31] It assesses user needs in 22 areas, divided into five categories: basic, health, functioning, social and service needs. The CAN evaluates needs by taking into account their number and their severity. For the MANQ (Cronbach Alpha $=0.70$ to 0.73 ), four areas were added: stress adaptation (included as a health need), social exclusion (social need), involvement in treatment decisions (service need), and job integration (basic need) for a total of 26 areas (Table 1). Unlike the CAN, which assesses the interviews and measures users' needs with ordinal scales (0 to 2; or yes/no), the MANQ uses 11-point analog scales, ranging from 0 (no need) to 10 (severe need). Users answer questions with the help of the interviewers. These changes reflect the new recovery paradigm that is at the heart of current mental health reforms [13,14] and enhance data variability. The MANQ also includes items related to socio-demographic and socio-economic user profiles. The validation of the MANQ was the subject of a previous publication [61].

The six other standardized instruments used for this study both at T0 and TI are described in detail in Table 1: the Social Provisions Scale (SPS), the Multnomah Community Ability Scale (MCAS), the Alcohol Use Disorders Identification Test (AUDIT), the Drug Abuse Screening Test-20 (DAST-20), the Alberta Continuity of Services Scale for Mental Health (ACSS-MH), and the Service Utilization Questionnaire (SUQ).

\section{Analysis and conceptual framework}

To reduce errors in building data files, questionnaire data were collected scanning with TELFORM ${ }^{\circ}$ software, and automatically loaded in SPSS files. A research assistant validated each file entry. Data was thoroughly cleaned before going through analyses. Verification of normality assumptions for every continuous variable revealed that no variable transformation was necessary.

Analyses followed the conceptual framework displayed on Figure 1, based on previous research and especially on Caron's SQOL framework [73]. The dependent variable was the SQOL, measured with the SLDS instrument at T1. Predictors $(\mathrm{N}=32)$, collected at $\mathrm{T} 0$, were organized in six categories: socio-demographic variables, clinical variables, needs and functionality variables, negative life events variables, social support variables, and healthcare service use and appreciation variables. The chosen predictors take into consideration all the aspects that, according to previous studies, could influence a change in SQOL among users with severe mental disorders. As regards scores from the Social Provision Scale, sub-scale scores allowed subtler analyses based on the categorization by Cutrona and Russell [62] in attachment, social 
Table 1 Standardized instruments used

\begin{tabular}{ll}
\hline Name & Description \\
\hline Satisfaction with Life Domains & Assesses satisfaction in 20 life domains; seven-point \\
Scale (SLDS) [6] & Likert scale, questions; Cronbach alpha: 0.92 [60] \\
Montreal Assessment of Needs & Derived from the Camberwell Assessment of Need (CAN) \\
Questionnaire (MANQ) [61] & Assesses user needs in 26 needs areas; 11 -point analog scales \\
& $(0-10) ;$ Cronbach Alpha: 0.70 to 0.73
\end{tabular}

\begin{tabular}{|c|c|c|}
\hline & & Civil status \\
\hline & & Education \\
\hline & & Employment \\
\hline & & Type of housing (autonomous/supervised) \\
\hline & & Nationality (Canadian/Others) \\
\hline & & Spoken language (French/Others) \\
\hline & & Importance attributed to spirituality \\
\hline & & $\begin{array}{l}\text { Number of needs areas ( } 26 \text { in five categories: } \\
\text { basic; health; functioning; social, services) }\end{array}$ \\
\hline & & Severity of need \\
\hline & & Amount of help received from relatives \\
\hline & & Amount of help received from services \\
\hline & & Adequacy of help received \\
\hline Social Provision Scale (SPS) [62] & $\begin{array}{l}\text { Measures availability of social support in six dimensions; } \\
\text { Cronbach Alpha: } 0.92 \text { [62] }\end{array}$ & $\begin{array}{l}\text { Attachment, reassurance of worth, social } \\
\text { integration, reliable alliance, guidance and } \\
\text { nurturance }\end{array}$ \\
\hline $\begin{array}{l}\text { Multnomah CommunityAbility } \\
\text { Scale (MCAS) [63] }\end{array}$ & $\begin{array}{l}\text { Assesses user's functional ability in the community, e.g. obstacles } \\
\text { to functioning, social competences; Cronbach Alpha: } 0.87 \text { [63] }\end{array}$ & Functional ability in the community \\
\hline $\begin{array}{l}\text { Alcohol Use Disorders } \\
\text { Identification Test (AUDIT) [64] }\end{array}$ & $\begin{array}{l}\text { Measures alcohol consumption level and consequences; } \\
10 \text { items; yes/no questions; Cronbach Alpha: } 0.88 \text { [65] }\end{array}$ & Alcohol abuse \\
\hline $\begin{array}{l}\text { Drug Abuse Screening Test } \\
\text { (DAST-20) [66] }\end{array}$ & $\begin{array}{l}\text { Measures user's drug use and consequences; } 20 \text { items; yes/no } \\
\text { questions; Cronbach Alpha: } 0.74 \text { [66] }\end{array}$ & Drug Abuse \\
\hline $\begin{array}{l}\text { Alberta Continuity of Services } \\
\text { Scale for Mental Health (ACSS-MH) [67] }\end{array}$ & $\begin{array}{l}\text { Measures service continuity, e.g. system access and team } \\
\text { function; Cronbach Alpha: } 0.78 \text { to } 0.92\end{array}$ & Service continuity \\
\hline $\begin{array}{l}\text { Service Utilization Questionnaire } \\
\text { (SUQ) [68] }\end{array}$ & $\begin{array}{l}\text { Derived from the Canadian Health Survey Questionnaire } \\
\text { (CCHS) Evaluates types and frequency of professionals } \\
\text { and services used }\end{array}$ & $\begin{array}{l}\text { Visit to any healthcare professional or } \\
\text { services }\end{array}$ \\
\hline Clinical records & Diagnoses & Schizophrenia \\
\hline & & Mood disorders \\
\hline & & Anxiety disorders \\
\hline & & Personality disorders \\
\hline & & Delusion and other psychotic disorders \\
\hline & & Schizophrenia spectrum disorders \\
\hline & & Number of mental disorders \\
\hline & & History of prior violence \\
\hline & & $\begin{array}{l}\text { History of prior judiciary problems Being } \\
\text { on medication }\end{array}$ \\
\hline
\end{tabular}

integration, reassurance of worth, reliable alliance, guidance, and opportunity for nurturance.

Univariate analyses comprised frequency distribution for categorical variables and mean values for continuous variables to describe participants in the sample. A hierarchical linear regression model was used for an Alpha value set at 0.05 . The hierarchical model permitted

Variables

Subjective quality of life

Age

Gender

Civil status

Education

Employment

Nationality (Canadian/Others)

Spoken language (French/Others)

portance attributed to spirituality

basic; health; functioning; social, services)

Severity of need

Adequacy of help received ce and

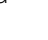




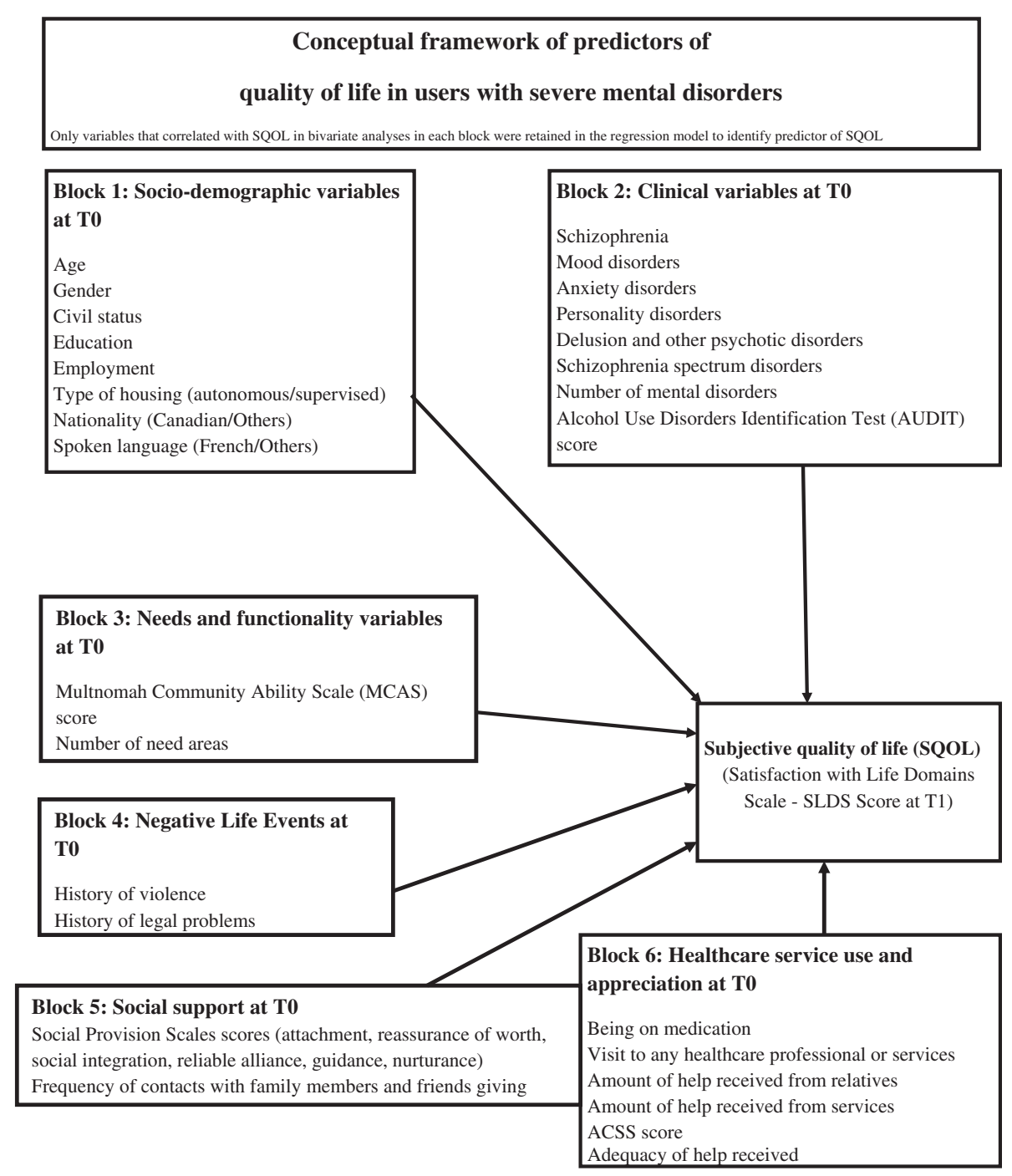

Figure 1 Conceptual framework of predictors of quality of life in users with severe mental disorders.

regression model. Goodness-of-fit and total variance explained were generated for each block as well as the entire model. In order to avoid multi-colinearity between explanatory variables, their relationships were checked using two tests: Collinearity diagnostic and Tolerance. Tolerance is the opposite of the variance inflator factor (VIF). A VIF close to the 10.0 is a reflection of collinearity between variables, as is a tolerance close to 0.1. Lastly, further analysis consisted in assessing predictors of SQOL by taking into account only needs variables. A hierarchical linear regression model was also used for this purpose.

\section{Results}

\section{User sample}

Overall, 437 users were recruited at baseline (T0), with $352(80.5 \%)$ consenting, all of whom were contacted for a second series of interviews 18 months later (T1). The characteristics of the users recruited at T0 were described in a previous study [74-76].

A total of 297 users (84.4\%) agreed to participate at T1, whereas 16 (4.5\%) users refused to do so, seven (2.0\%) were excluded due to incapacity, six $(1.7 \%)$ were deceased, and $26(7.4 \%)$ had moved outside of the study area or could no longer be found. Comparison analyses between the 55 users who did not take part in the follow-up survey and the remaining 297 participants yielded no significant differences in terms of age distribution $(P=0.409)$, gender distribution $\left(X^{2}=0.325, \mathrm{P}=0.58\right.$ ), or type of housing (autonomous versus supervised: $\left.X^{2}=0.406 ; \mathrm{P}=0.524\right)$. Participants who took part in both the baseline (T0) and follow-up (T1) surveys were also compared to those who responded only to the baseline assessment with respect to the most frequent mental health disorders, and no significant differences were found (schizophrenia: $X^{2}=0.043, \mathrm{P}=0.835$; schizophrenia 
spectrum disorders: $X^{2}=0.015, \mathrm{P}=0.901$; mood disorders: $X^{2}=2.170, \quad \mathrm{P}=0.141$; delusion disorders: $X^{2}=0.259$, $\mathrm{P}=0.611$; anxiety disorders: $X^{2}=0.547 ; \mathrm{P}=0.460$ ).

In total, 153 males (51.5\%) and 144 females (48.5\%) participated in the study, with a mean age of 48 years (SD: 10.4), as shown in Table 2. A majority of users (64.0\%) were French-speaking and single (75.4\%). Two-thirds had completed primary or secondary school (62.3\%). Most users $(60.5 \%)$ lived in autonomous housing. The most prevalent severe mental health disorders were mood disorders (41.8\%), followed by schizophrenia (38.0\%), schizophrenia spectrum disorders (12.8\%) and delusion and other psychotic disorders (9.4\%). Most participants had also a second diagnosis of mental disorder, the most common being a personality disorder (27.3\%). The majority of users suffering from schizophrenia $(\mathrm{N}=73$ or $61.9 \%)$ lived in supervised housing, and most users having another severe mental disorder lived in autonomous housing ( $\mathrm{N}=136$ or $74.7 \%)$.

Table 3 shows the number and severity of user needs. The five most reported needs were psychological distress
(68.7\%), stress adaptation (61.3\%), physical health (56.6\%), psychotic symptoms (48.5\%), and money (47.1\%). In regard to the severity of needs, the highest means were related to job integration (mean: 7.5), childcare (7.5), drugs (7.4), sexual expression (7.4) and intimate relationships (7.3).

\section{SQOL predictors}

Table 4 shows the hierarchical linear regression model. The category related to needs and functionality variables is the best predictor of QOL. Two variables, severity of needs and MCAS scores, together accounted for $11.8 \%$ of QOL and had a negative impact on QOL. However, the MCAS beta scores were not significant in final analyses. The socio-demographic variables were the second best predictor of QOL, accounting for nearly $8 \%$ of the variance; autonomous housing was retained, and it was found to have a negative impact on QOL. Social support variables accounted for $7.9 \%$ of the variance; perception of availability of social integration and reassurance of worth supports had a positive link with

Table 2 Socio-demographic, socio-economic and clinical variables $(N=297)$

\begin{tabular}{|c|c|c|c|c|}
\hline Categories & Sub-categories & Variables & $\mathbf{n}$ & $\%$ \\
\hline \multirow[t]{10}{*}{ Sociodemographic variables } & Age [Mean (SD)] & & 48.5 & 10.4 \\
\hline & Gender & Men & 153 & 51.5 \\
\hline & & Women & 144 & 48.5 \\
\hline & Spoken language & French & 190 & 64.0 \\
\hline & & English & 61 & 20.5 \\
\hline & & French/English & 7 & 2.4 \\
\hline & & Others & 37 & 12.5 \\
\hline & Civil status & Single/Never married & 224 & 75.4 \\
\hline & & In a relationship/Married/Remarried & 33 & 11.1 \\
\hline & & Separated/Divorced/Widow & 40 & 13.5 \\
\hline \multirow[t]{4}{*}{ Socio-economic variables } & Type of housing & Autonomous housing & 179 & 60.3 \\
\hline & & Supervised housing & 116 & 39.1 \\
\hline & Education & Primary/Secondary school & 185 & 62.3 \\
\hline & & College/University & 110 & 37.0 \\
\hline \multirow[t]{11}{*}{ Clinical variables } & Severe mental health disorders & Schizophrenia & 113 & 38.0 \\
\hline & & Mood disorders & 124 & 41.8 \\
\hline & & Schizophrenia spectrum disorders & 38 & 12.8 \\
\hline & & Delusional and other psychotic disorders & 28 & 9.4 \\
\hline & Second diagnosis & Anxiety disorders & 36 & 12.1 \\
\hline & & Dependences and substance abuse & & \\
\hline & & Drug & 16 & 5.4 \\
\hline & & Alcohol & 13 & 4.4 \\
\hline & & Multiple & 27 & 9.1 \\
\hline & & Personality disorders & 81 & 27.3 \\
\hline & & Moderate or mild mental retardation & 37 & 12.5 \\
\hline
\end{tabular}


Table 3 Number and severity of needs of participants according to the MANQ $(\mathbf{N}=297)$

\begin{tabular}{|c|c|c|c|c|c|}
\hline Categories & Areas & $\mathrm{N}$ & $\%$ & Severity Mean* & SD \\
\hline \multirow[t]{4}{*}{ Basic } & Job integration & 101 & 34.0 & 7.50 & 2.504 \\
\hline & Accommodation & 101 & 34.0 & 5.96 & 3.062 \\
\hline & Daytime activities & 98 & 33.0 & 5.52 & 2.729 \\
\hline & Food & 96 & 32.3 & 5.24 & 2.396 \\
\hline \multirow[t]{8}{*}{ Health } & Psychological distress & 204 & 68.7 & 6.67 & 2.732 \\
\hline & Stress adaptation & 182 & 61.3 & 6.30 & 2.599 \\
\hline & Physical health & 168 & 56.6 & 5.70 & 2.851 \\
\hline & Psychotic symptoms & 144 & 48.5 & 5.54 & 2.715 \\
\hline & Drugs & 99 & 33.3 & 7.44 & 3.035 \\
\hline & Safety to self & 58 & 19.5 & 6.00 & 2.853 \\
\hline & Alcohol & 31 & 10.4 & 5.10 & 2.371 \\
\hline & Safety to others & 22 & 7.4 & 5.77 & 3.206 \\
\hline \multirow[t]{5}{*}{ Functioning } & Money & 140 & 47.1 & 6.84 & 2.904 \\
\hline & Looking after the home & 99 & 33.3 & 5.69 & 2.448 \\
\hline & Self-care & 49 & 16.5 & 5.55 & 2.829 \\
\hline & Basic education & 42 & 24.1 & 5.79 & 3.000 \\
\hline & Childcare & 21 & 7.1 & 7.43 & 2.993 \\
\hline \multirow[t]{4}{*}{ Social } & Sexual expression & 122 & 41.1 & 7.42 & 2.787 \\
\hline & Company & 101 & 34.0 & 4.06 & 3.736 \\
\hline & Intimate relationships & 97 & 32.7 & 7.30 & 2.84 \\
\hline & Social exclusion & 95 & 32.0 & 6.16 & 2.841 \\
\hline \multirow[t]{5}{*}{ Services } & Transportation & 65 & 21.9 & 7.12 & 3.059 \\
\hline & Information about illness and treatment & 65 & 21.0 & 5.94 & 2.800 \\
\hline & Involvement in treatment decisions & 58 & 19.5 & 6.12 & 2.986 \\
\hline & Benefits & 30 & 10.1 & 6.87 & 3.126 \\
\hline & Telephone & 8 & 2.7 & 6.38 & 2.615 \\
\hline
\end{tabular}

* Severity range from 0 to 10 (10 was the highest).

QOL. Finally, two clinical variables explained $4.9 \%$ of the variance: a diagnosis of schizophrenia had a positive link to QOL while DAST-20 scores were negatively related. No variables were retained from the fourth (negative life events) and sixth (healthcare service use and appreciation) blocks. For the entire model, the total variance explained was $37 \%$, with an acceptable goodness-of-fit $(\mathrm{P}<0.001)$. No sign of multi-colinearity was detected (tolerance coefficients were over 0.7 , and VIF coefficients were under 2.0).

Table 5 shows the areas of need identified as SQOL predictors. Health needs account for $9.7 \%$ of the variance of the model. It includes safety to self, stress adaptation and drugs. However, only safety to self retained a significant beta in final analyses and was negatively related to SQOL. However drugs showed a tendency to be positively related to SQOL. Service needs accounted for $8.2 \%$ of the variance, but only benefits showed a tendency to be negatively related to SQOL in the final analyses. Social needs explained $5.4 \%$ of the variance; need for company and social exclusion had a negative relation to SQOL. Among the basic needs that explained $5.2 \%$ of the variance, daytime activities was the only negative predictor of SQOL. Finally, among basic needs (1.5\%), only self-care showed a negative relationship in the initial analyses, but its beta was no longer significant in the full model. The total variance explained was 30\%, with an acceptable goodness-of-fit $(\mathrm{P}<0.001)$. No sign of multi-colinearity was detected (tolerance coefficients were over 0.7, and VIF coefficients were under 2.0).

\section{Discussion}

This article aimed to identify 1) the predictors of SQOL of a heterogeneous cohort of users with severe mental disorders over an 18-month period, and 2) the areas of need that are the main predictors of the SQOL. We hypothesized that the severity of needs would be the strongest SQOL predictor for these users, and out of the 
Table 4 Predictors of SQOL in users with mental disorders: Hierarchical linear regression analysis

\begin{tabular}{|c|c|c|c|c|c|c|c|c|c|c|c|c|c|}
\hline \multirow{3}{*}{ Predictors from baseline } & \multicolumn{2}{|c|}{$\begin{array}{c}\text { Sociodemographic } \\
\text { variables }\end{array}$} & \multicolumn{2}{|c|}{$\begin{array}{c}\text { Clinical } \\
\text { variables }\end{array}$} & \multicolumn{2}{|c|}{$\begin{array}{c}\text { Needs and } \\
\text { functionaliy variables }\end{array}$} & \multicolumn{7}{|c|}{ Social support } \\
\hline & \multirow[t]{2}{*}{$\bar{\beta}$} & \multirow[t]{2}{*}{$P$} & \multirow[t]{2}{*}{$\bar{\beta}$} & \multirow[t]{2}{*}{$P$} & \multirow[t]{2}{*}{$\bar{\beta}$} & \multirow[t]{2}{*}{$P$} & \multirow[t]{2}{*}{$\bar{\beta}$} & \multirow[t]{2}{*}{$\mathrm{t}$} & \multirow[t]{2}{*}{$\mathbf{P}$} & \multicolumn{2}{|c|}{$95 \% \mathrm{Cl}$} & \multicolumn{2}{|c|}{$\begin{array}{c}\text { 95\% Cl Colinearity } \\
\text { statistics }\end{array}$} \\
\hline & & & & & & & & & & $\mathrm{LL}$ & UL & Tolerance & VIF \\
\hline $\begin{array}{l}\text { Type of housing } \\
\text { (autonomous) }\end{array}$ & -.282 & .000 & -.199 & .001 & -.151 & .008 & -.160 & -2.937 & .004 & -10.713 & -2.116 & .787 & 1.271 \\
\hline Schizophrenia & & & .181 & .002 & .155 & .006 & .166 & 3.142 & .002 & 2.497 & 10.873 & .837 & 1.195 \\
\hline DAST-20 score & & & -.147 & .008 & -.074 & .157 & -.101 & -2.020 & .044 & -1.395 & -.018 & .934 & 1.071 \\
\hline Severity of needs & & & & & -.330 & .000 & -.272 & -5.176 & .000 & -.226 & -.101 & .847 & 1.180 \\
\hline MCAS score & & & & & .111 & .036 & .079 & 1.566 & .118 & -.041 & .361 & .920 & 1.086 \\
\hline Social integration & & & & & & & .196 & 3.472 & .001 & .942 & 3.410 & .732 & 1.366 \\
\hline Reassurance of worth & & & & & & & .136 & 2.397 & .017 & .255 & 2.597 & .721 & 1.386 \\
\hline Total variance explained (R2) & \multicolumn{2}{|r|}{$8.0 \%$} & \multicolumn{2}{|c|}{$12.9 \%$} & \multicolumn{2}{|r|}{$24.7 \%$} & \multicolumn{7}{|c|}{$32.6 \%$} \\
\hline \multicolumn{14}{|l|}{ Goodness-of-fit } \\
\hline $\mathrm{F}$ & \multicolumn{2}{|r|}{25.518} & \multicolumn{2}{|c|}{14.523} & \multicolumn{2}{|r|}{19.133} & \multicolumn{7}{|c|}{19.940} \\
\hline$P$ & \multicolumn{2}{|r|}{$<0.001$} & \multicolumn{2}{|c|}{$<0.001$} & \multicolumn{2}{|r|}{$<0.001$} & \multicolumn{7}{|c|}{$<0.001$} \\
\hline
\end{tabular}

needs categories, that social needs would be the best predictors of SQOL.

Overall, our conceptual framework predicted SQOL at an acceptable level (33\% of the variance explained) comparable to or higher than most SQOL studies especially considering the diversity of the sample, which reflected the full spectrum of users with severe mental disorders living in the community $[3,18,77]$. In accordance with our first hypothesis, the strongest predictor of SQOL was found to be the severity of needs: the less severe the needs, the higher the SQOL. This result compares with previous studies, which found that unmet needs (serious problems) [24,78-80] had a highly negative impact on SQOL. Findings using the CAN as the needs instrument made a distinction between serious problems, moderate problems and absence of needs $[24,47,81,82]$. In our study, we changed this ordinal scale to an 11-point analog scale, ranging from 0 to 10 . Our results confirm that SQOL is

Table 5 Severity of needs predicting SQOL in users with mental disorders: Hierarchical linear regression analysis

\begin{tabular}{|c|c|c|c|c|c|c|c|c|c|c|c|c|c|c|c|}
\hline & \multicolumn{2}{|c|}{ Services } & \multicolumn{2}{|c|}{ Functioning } & \multicolumn{2}{|c|}{ Health } & \multicolumn{2}{|c|}{ Basic } & \multicolumn{7}{|c|}{ Social needs } \\
\hline & \multirow[t]{2}{*}{ b } & \multirow[t]{2}{*}{$P$} & \multirow[t]{2}{*}{ b } & \multirow[t]{2}{*}{$\mathbf{P}$} & \multirow[t]{2}{*}{ b } & \multirow[t]{2}{*}{$P$} & \multirow[t]{2}{*}{ b } & \multirow[t]{2}{*}{$\mathbf{P}$} & \multirow[t]{2}{*}{ b } & \multirow[t]{2}{*}{$\mathrm{t}$} & \multirow[t]{2}{*}{$P$} & \multicolumn{2}{|c|}{$95 \mathrm{cpc} \mathrm{Cl}$} & \multicolumn{2}{|c|}{ Colinearity statistics } \\
\hline & & & & & & & & & & & & $\mathrm{LL}$ & UL & Tolerance & VIF \\
\hline Benefit & -.185 & .001 & -.191 & .001 & -.146 & .009 & -.126 & .020 & -.101 & -1.936 & .054 & -1.740 & .014 & .895 & 1.117 \\
\hline Involvement in treatment decisions & -.185 & .001 & -.177 & .002 & -.112 & .044 & -.082 & .131 & -.055 & -1.051 & .294 & -1.127 & .342 & .878 & 1.139 \\
\hline Self-care & & & -.122 & .029 & -.097 & .070 & -.064 & .222 & -.020 & -.382 & .703 & -1.014 & .685 & .902 & 1.109 \\
\hline Safety to self & & & & & -.205 & .000 & -.190 & .000 & -.155 & -2.940 & .004 & -1.878 & -.372 & .880 & 1.137 \\
\hline Stress adaptation & & & & & -.173 & .002 & -.104 & .066 & -.030 & -.531 & .596 & -.753 & 433 & .757 & 1.320 \\
\hline Drugs & & & & & .126 & .020 & .102 & .052 & .091 & 1.803 & .072 & -.042 & .952 & .950 & 1.052 \\
\hline Daytime activities & & & & & & & -.251 & .000 & -.183 & -3.171 & .002 & -1.908 & -.447 & .736 & 1.358 \\
\hline Company & & & & & & & & & -.225 & -3.730 & .000 & -1.843 & -.570 & .673 & 1.486 \\
\hline Social exclusion & & & & & & & & & -.113 & -2.057 & .041 & -1.312 & -.029 & .811 & 1.233 \\
\hline Total variance explained (R2) & \multicolumn{2}{|c|}{$8.2 \%$} & \multicolumn{2}{|c|}{$9.7 \%$} & \multicolumn{2}{|c|}{$19.4 \%$} & \multicolumn{2}{|c|}{$24.6 \%$} & \multicolumn{7}{|c|}{$30.0 \%$} \\
\hline \multicolumn{16}{|l|}{ Goodness-of-fit } \\
\hline $\mathrm{F}$ & \multicolumn{2}{|c|}{13.107} & \multicolumn{2}{|c|}{10.467} & \multicolumn{2}{|c|}{11.664} & \multicolumn{2}{|c|}{13.503} & \multicolumn{7}{|c|}{13.646} \\
\hline$P$ & \multicolumn{2}{|c|}{$<0.001$} & \multicolumn{2}{|c|}{$<0.001$} & \multicolumn{2}{|c|}{$<0.001$} & \multicolumn{2}{|c|}{$<0.001$} & & & & $<0$ & 001 & & \\
\hline
\end{tabular}

Variables entered into blocks: Block 1 or Services: Information about illness and treatment, telephone, transport, benefits, involvement in treatment decisions; Block 2 or Functioning: Looking after the home, self-care, basic education, money, childcare; Block $\mathbf{3}$ or Health: Psychotic symptoms, physical health, drugs, alcohol, safety to self, safety to others, psychological distress, stress adaptation; Block $\mathbf{4}$ or Basic needs: Accommodation, food, daytime activities, job integration; Block 5 or Social needs: Company, intimate relationships, sexual expression, social exclusion. 
influenced by serious problems, but also by moderate problems in some needs areas. Furthermore, in contrast to previous studies [26,28], we did not find a significant association between SQOL and the number of needs. This could indicate that some needs areas (e.g. company) may have a greater impact on SQOL than others.

SQOL is associated with two areas of social support: reassurance of worth and social integration. Reassurance of worth indicates acknowledgement of competence and skills by others [62]. According to the literature, reassurance of worth is an exceptionally strong predictor of SQOL among users with severe mental disorders, as it is among poorer groups and the general population $[37,83]$. Social integration indicates that the individual shares common interests and activities with a network of friends $[66,84]$, and is less likely to experience loneliness or social isolation [84].

Two clinical variables were identified as predictors of SQOL: schizophrenia and lower drug use and consequences according to the DAST-20 scores. The link between a schizophrenia diagnosis and higher SQOL was unexpected. It could be explained by the fact that users with schizophrenia constituted a minority of our sample and that most of them had no other mental disorder. Most studies concerning SQOL included mainly or exclusively users with schizophrenia, with some of them also presenting a second diagnosis, such as a mood disorder. Furthermore, a previous study by Caron et al. [37] found that users with schizophrenia reported a comparable SQOL to the general population. Their level of satisfaction resulted from community mental health programs, access to supervised apartments, higher welfare benefits compared to non-disabled recipients, and ability to rely on professionals for advice and emotional support. Users with schizophrenia may also be more satisfied with their SQOL because they have fewer personal projects and less desire for change than users suffering from other severe mental disorders [45]. SQOL is thus independent of the standard of living (Objective QOL) among users with schizophrenia [85]. Users with chronic schizophrenia can be satisfied with their SQOL despite living conditions that would be considered unpleasant to clinicians or the general population [86]. Additionally, according to Ruggeri et al. [18], users with schizophrenia tend to overestimate their level of functioning. The association between reduced drug use and consequences according to the DAST-20 score and better SQOL makes sense. Dual diagnoses usually result in poorer outcomes [87]. Substance abuse increases violence and medication non-compliance among users with severe mental disorders, and exacerbates the actual symptoms of schizophrenia [27]. Users with a dual diagnosis have a poorer SQOL than those who have only a single diagnosis of either severe mental disorder or substance abuse $[27,88]$.
A single socio-demographic variable had any kind of connection with SQOL: users living in supervised housing reported a better SQOL. This result seems in opposition with literature that has reported a link between SQOL and autonomous housing [47]. Some previous studies, however, have reported that supervised housing positively influences SQOL [21,49]. Indeed, according to the residential continuum model, users are matched with the type of residential services corresponding to their service needs and psychiatric impairment, and are transferred progressively into more autonomous housing situations if and when their condition improves [48,50]. Some previously hospitalized users may be satisfied with living in supervised housing [21]. Furthermore, according to Priebe [86], comparing one's living situation with original aspirations and expectations, matching up one's own position with that of others, and adaptation over time are the three main processes that influence one's perceived SQOL. It may be that users living in supervised housing express few worries or little desire for change when comparing their housing situation to that of persons living in autonomous housing because some of their previous goals have become less relevant over time [21,45]. It could be the case of users with schizophrenia versus those affected by mood disorders or other severe mental disorders. In our sample, most users with schizophrenia lived in supervised housing. Lastly, when compared to users living in autonomous housing, users living in supervised housing are less likely to experience social loneliness.

In opposition to our second hypothesis according to which social needs would be the stronger SQOL predictors, it was health needs that contributed the most to the model. However, the only health need area associated with SQOL is safety to self. The link between SQOL and a lack of needs or rare serious problems in the area of safety to self is logical. Safety to self is one of the most common needs among users with a history of suicide attempts [89].

Table 4 confirms the importance of social needs areas as SQOL predictors. According to Lasalvia et al. [24], a reduction of unmet social needs predicts an increase in the SQOL. Of the four areas of needs that have a negative impact on SQOL, two are in the social category: company and social exclusion. The absence of needs or few serious problems in those two areas are signs of genuine social integration, which is essential to a higher SQOL [66]. As noted in previous studies, company is the area of need most strongly associated with a poorer SQOL $[24,26,82]$.

Daytime activities are a basic need, but the absence of needs or few serious problems in that area are also indicative of healthy social integration. Daytime activities help to build social networks and create friendships. According to previous studies with the CAN using factor analysis, daytime activities and company are often included 
in the same need factor $[90,91]$. Benefits are a service need but are also indirectly associated with reassurance of worth and social integration. Reassurance of worth is lower among users who do not have a meaningful economic role [37]; such is the case for those expressing a need in the area of benefits. Social loneliness and stigmatization often occur among users who need benefits. Like daytime activities, employment helps to develop a social network [92].

Finally, it is interesting to note that needs with higher average severity (job integration, childcare, etc.) do not significantly alter SQOL. Conversely, the need for company is the one having the lowest average severity. This indicates that the presence of a moderate problem in this area is sufficient to affect SQOL significantly.

\section{Limitations}

Our study includes certain notable limitations. First, time from T0 to T1 was relatively short (18 months). Secondly, as our sample represented a heterogeneous group of users with severe mental disorders (which is also a strength), the results may not be applicable to a sample constituted exclusively of users with schizophrenia or other specific diagnosis. Third, the study did not take into account the duration of the severe mental disorder from the time when it was first diagnosed. Finally, it would had been interesting to measure what produced the variations in SQOL between $\mathrm{T} 0$ and $\mathrm{T} 1$ or to identify predictors of SQOL decrease or increase in T1, which is another relevant question. Other studies are needed to complement our research with regard to these aspects.

\section{Conclusion}

This longitudinal study is one of the first to test such a large number of variables that can predict SQOL in a cohort of users with severe mental disorders. Based on previous research, a comprehensive conceptual framework was developed that summarized possible predictors of SQOL. Further studies could build on this framework. This study is also among the few to compare SQOL within a heterogeneous cohort of users representing the full spectrum of serious mental disorders and living in the community. It found that the severity of needs is the strongest SQOL predictor among this group and that SQOL is most often associated with health needs. Meeting these serious needs should be the priority of mental health services. Moreover, a moderate problem in the social needs category is enough to predict a negative SQOL - which is a key finding as most studies have essentially focused on the importance of unmet needs (or serious problems). Specifically, company was the area that most significantly altered SQOL. Furthermore, when compared with users affected by other severe mental disorders, users with schizophrenia had a better SQOL. Users living in supervised housing had better SQOL than those living in autonomous housing. Finally, the study confirms the significant impact on SQOL of social integration and reassurance of worth - two aspects of social support. Priority should be given to programs and interventions that promote reliable and supportive social networks enabling social integration, reassurance of worth, and feelings of personal safety. In addition, residential services matching the level of functioning of users should be maintained or developed.

\section{Abbreviations}

ACSS-MH: Alberta Continuity of Services Scale for Mental Health; AUDIT: Alcohol use disorders identification test; CAN: Camberwell assessment of need; CCHS: Canadian community health survey; DAST20: Drug abuse screening test-20; HSSC: Health and social services centers; MANQ: Montreal assessment of needs questionnaire; MCAS: Multnomah community ability scale; MHUI: Mental Health University Institute;

QOL: Quality of life; SUQ: Service utilization questionnaire; SLDS: Satisfaction with life domains scale; SPS: Social provision scale; SQOL: Subjective quality of life.

\section{Competing interests}

The authors declare that they have no competing interests.

\section{Authors' contributions}

MJF and GG designed the study. JMB carried out the statistical analyses with assistance from JC, NS and JT. MJF and GG wrote the article. All authors have read and approved the final manuscript.

\section{Acknowledgements}

The study was funded by the Canadian Institute of Health Research (CIHRMOP-84512). We would like to thank this granting agency, and all the users and organizations who participated in the research.

Received: 7 February 2013 Accepted: 3 June 2013

Published: 8 June 2013

\section{References}

1. Bengtsson-Tops A, Hansson L, Sandlund M, Bjarnason O, Korkeila J, Merinder L, Nilsson L, Sorgaard KW, Vinding HR, Middelboe T: Subjective versus interviewer assessment of global quality of life among persons with schizophrenia living in the community: a Nordic multicentre study. Qual Life Res 2005, 14:221-229.

2. Caron J, Mercier C, Diaz P, Martin A: Socio-demographic and clinical predictors of quality of life in patients with schizophrenia or schizo-affective disorder. Psychiatry Res 2005, 137:203-213.

3. Evans $S$, Huxley P, Priebe $S$ : A comparison of the quality of life of severely mentally ill people in UK \& German samples. Int I Soc Psychiatry 1999, 46:47-56.

4. Ruggeri $M$, Nosè $M$, Bonetto $C$, Cristofalo $D$, Lasalvia $A$, Salvi $G$, Stefani $B$, Malchiodi F, Tansella M: Changes and predictors of change in objective and subjective quality of life: multiwave follow-up study in community psychiatric practice. Br J Psychiatry 2005, 187:121-130.

5. Gupta S, Kulhara P, Verma SK: Quality of life in schizophrenia and dysthemia. Acta Psychiatr Scand 1998, 97:290-296.

6. Baker F, Intagliata J: Quality of life in the evaluation of community support systems. Eval Program Plann 1982, 5:69-79.

7. Lehman AF, Ward NC, Linn LS: Chronic mental patients: the quality of life issue. Am J Psychiatry 1982, 139:1271-1276.

8. Sullivan $G$, Wells KB, Leake B: Quality of life of seriously mental ill persons in Mississipi. Hosp Community Psychiatry 1991, 42:752-754.

9. Pinkney AA, Gerber GJ, Lafave HG: Quality of life after psychiatric rehabilitation: the clients' perspectives. Acta Psychiatr Scand 1991, 83:86-91.

10. Barry MM, Zissi A: Quality of life as an outcome measure in evaluating mental health services: a review of the empirical evidence. Soc Psychiatry Psychiatr Epidemiol 1997, 32:38-47. 
11. Heider D, Angermeyer MC, Winkler I, Schomerus G, Bebbington PE, Brugha T, Azorin JM, Toumi M: A prospective study of Quality of life in schizophrenia in three European countries. Schizophr Res 2007, 93:194-202.

12. Lam JA, Rosenheck RA: Correlates of improvement in quality of life among homeless persons with serious mental illness. Psychiatr Serv 2000, 51:116-118.

13. Piat M, Sabetti J, Bloom D: The transformation of mental health services to a recovery-oriented system of care: Canadian decision maker perspectives. Int J Soc Psychiatry 2010, 56:168-177.

14. Kirby MJL: Out of the shadows at last, The Standing Senate Committe on Social Affairs. SaT edth edition. Ottawa: The Senate of Canada; 2006:28. pp. 281.

15. Anthony WA: Recovery from the mental illness: the guiding vision of the mental health service system in the 1990s. Psychosocial Rehabilitation Journal 1993, 16:11-23.

16. Arnold LM, Witzeman KA, Swank ML, McElroy SL, Keck PEJ: Health-related quality of life using the SF-36 in patients with bipolar disorder compared with patients with chronic back pain and the general population. J Affect Disord 2000, 57:235-239.

17. Cramer V, Torgersen S, Kringlen E: Mood disorders and quality of life. A community study. Nord J Psychiatry 2010, 64:58-62.

18. Ruggeri M, Gater R, Bisoffi G, Barbui C, Tansella M: Determinants of subjective quality of life in patients attending community-based mental health services. The South-Verona outcome project 5. Acta Psychiatr Scand 2002, 105:131-140.

19. Huppert JD, Weiss KA, Lim R, Pratt S, Smith TE: Quality of life in schizophrenia; contributions of anxiety and depression. Schizophr Res 2001, 51:171-180.

20. Narvaez JM, Twamley EW, McKibbin CL, Heaton RK, Patterson TL: Subjective and objective quality of life in schizophrenia. Schizophr Res 2008, 98:201-208.

21. Leisse M, Kallert TW: Social integration and the quality of life of schizophrenic patients in different types of complementary care. Eur Psychiatry 2000, 15:450-460.

22. Staring $A B$, Mulder $C L$, Duivenvoorden HJ, De Haan L, Van der Gaag M: Fewer symptoms vs. More side-effects in schizophrenia? opposing pathways between antipsychotic medication compliance and quality of life. Schizophr Res 2009, 113:27-33.

23. Holloway F, Carson J: Subjective quality of life, psychopathology, satisfaction with care and insight: an exploratory study. Int J Soc Psychiatry 1999, 45:259-267.

24. Lasalvia A, Bonetto C, Malchiodi F, Salvi G, Parabiaghi A, Tansella M, Ruggeri M: Listening to patients' needs to improve their subjective quality of life. Psychol Med 2005, 35:1655-1665.

25. Slade M, Leese M, Cahill S, Thornicroft G, Kuipers E: Patient-rated mental health needs and quality of life improvement. Br J Psychiatry 2005, 187:256-261.

26. Wiersma D, van Busschbach J: Are needs and satisfaction of care associated with quality of life? An epidemiological survey among the severely mentally ill in the Netherlands. Eur Arch Psychiatry Clin Neurosci 2001, 251:239-246.

27. Margolese HC, Carlos Negrete J, Tempier R, Gill K: A 12-month prospective follow-up study of patients with schizophrenia-spectrum disorders and substance abuse: Changes in psychiatric symptoms and substance use. Schizophr Res 2006, 83:65-75.

28. Björkman T, Hansson L: Predictors of improvement in quality of life of long-term mentally ill individuals receiving case management. Eur Psychiatry 2002, 17:33-40.

29. Lasalvia A, Bonetto C, Salvi G, Bissoli S, Tansella M, Ruggeri M: Predictors of changes in needs for care in patients receiving community psychiatric treatment: a 4-year follow-up study. Acta Psychiatrica Scandinavica Supplement 2007, 116:31-41.

30. Slade M, Leese M, Ruggeri M, Kuipers E, Tansella M, Thornicroft G: Does meeting needs improve quality of life? Psychother Psychosom 2004, 73:183-189.

31. Xiang YT, Wang CY, Chiu HF, Zhao JP QC, Chan SS, Lee EH, Ungavi GS: Socio-demographic and clinical determinants of quality of life in Chinese patients with schizophrenia: a prospective study. Qual Life Res 2010, 19:317-322.

32. Xiang $Y T$, Weng $Y Z$, Leung CM, Tang WK, Ungvari GS: Subjective quality of life in outpatients with schizophrenia in Honk Kong and Beijing: relationship to socio-demographic and clinical factors. Qual Life Res 2008, $17: 27-36$.
33. Huppert JD, Smith TE: Longitudinal analysis of subjective quality of life in schizophrenia: anxiety as the best symptom predictor. J Nerv Ment Dis 2001, 189:669-675.

34. Bengtsson-Tops A, Hansson L: Quantitative and qualitative aspects of the social network in schizophrenic patients living in the community. Relationship to sociodemographic characteristics and clinical factors and subjective quality of life. Int J Soc Psychiatry 2001, 47:67-77.

35. Priebe S, Roeder-Wanner UU, Kaiser W: Quality of life in first-admitted schizophrenia patients: a follow-up study. Psychol Med 2000, 30:225-230.

36. Baker F, Jodrey D, Intagliata J: Social support and quality of life of community support clients. Community Ment Health J 1992, 28:397-411.

37. Caron J, Tempier R, Mercier C, Leouffre P: Components of social support and quality of life in severely mentally ill, low income individuals and a general population group. Community Ment Health J 1998, 34:459-475.

38. Hansson L, Björkman T: Are factors associated with subjective quality of life in people with severe mental illness consistent over time- A 6-year follow-up study. Qual Life Res 2007, 16:9-16.

39. Kondrat DC, Early TJ: Battling in the trenches: case managers' ability to combat the effects of mental illness on consumers' perceived quality of life. Community Ment Health J 2011, 47:390-398.

40. Yanos PT, Rosenfield S, Horwitz AV: Negative and supportive social interactions and quality of life among persons diagnosed with severe mental illness. Community Ment Health J 2001, 37:405-419.

41. Ritsner MS, Lisker A, Arbitman M: Ten-year quality of life outcomes among patients with schizophrenia and schizoaffective disorders: I. Predictive value of disorder-related factors. Qual Life Res 2012, 21:837-847.

42. Eklund M, Hansson L, Bejerholm U: Relationships between satisfaction with occupational factors and health-related variables in schizophrenia outpatients. Soc Psychiatry Psychiatr Epidemiol 2001, 36:79-83.

43. Nordt C, Müller B, Rössler W, Lauber C: Predictors and course of vocational status, income, and quality of life in people with severe mental illness: A naturalistic study. Soc Sci Med 2007, 65:1420-1429.

44. Röder-Wanner UU, Oliver JP, Priebe S: Does quality of life differ in schizophrenic women and men? An empirical study. Int J Soc Psychiatry 1997, 43:129-143.

45. Mercier C, Péladeau N, Tempier R: Age, gender and quality of life. Community Ment Health J 1998, 34:487-500.

46. Kyle T, Dunn JR: Effects of housing circumstances on health, quality of life and healthcare use for people with severe mental illness: a review. Health Soc Care Community 2008, 16:1-15.

47. Browne $G$, Courtney M: Measuring the impact of housing on people with schizophrenia. Nurs Health Sci 2004, 6:37-44.

48. Wong $Y L$, Filoromo M, Tennille J: From principles to practice: A study of implementation of supported housing for psychiatric consumers. Adm Policy Ment Health 2007, 34:13-28.

49. Middelboe T, Mackeprang T, Thalsgaard A, Christiansen PB: A housing support programme for the mentally ill: need profile and satisfaction among users. Acta Psychiatr Scand 1998, 98:321-327.

50. Tsai J, Bond GR, Salyers MP, Godfrey JL, Davis KE: Housing preferences and choices among adults with mental illness and substance use disorders: a qualitative study. Community Ment Health J 2010, 46:381-388.

51. Taylor RE, Leese M, Clarkson P, Holloway F, G T: Quality of life outcomes for intensive versus standard community mental health services. PRISM Psychosis Study 9. Br J Psychiatry 1998, 173:416-422.

52. Skantze K: Subjective quality of life and standard of living: a 10-year follow-up of out-patients with schizophrenia. Acta Psychiatr Scand 1998, 98:390-399.

53. Huxley P, Evans S, Burns T, Fahy T, Green J: Quality of Life outcome in a randomized controlled trial of case management. Soc Psychiatry Psychiatr Epidemiol 2001, 36:249-255.

54. Ritsner MS, Arbitman M, Lisker A, Ponizovsky AM: Ten-year quality of life outcomes among patients with schizophrenia and schizoaffective disorder II. Predictive value of psychosocial factors. Qual Life Res 2012, 21:1075-1084.

55. Ritsner M, Gibel A, Ratner Y: Determinants of changes in perceived quality of life in the course of schizophrenia. Qual Life Res 2006, 15:515-526.

56. Ritsner M: Predicting changes in domain-specific quality of life of schizophrenia patients. J Nerv Ment Dis 2003, 19:287-294.

57. Ritsner MS, Lisker A, Arbitman M, Grinshpoon A: Factor structure in the Camberwell Assessment of Need-Patient version: the correlations with dimensions of illness, personality and quality of life of schizophrenia patients. Psychiatry Clin Neurosci 2012, 66:499-507. 
58. Fitzgerald PB, de Castella AR, Filia K, Collins J, Brewer K, Williams CL, Davey P, Kulkarni J: A longitudinal study of patient- and observer-rated quality of life in schizophrenia. Psychiatry Res 2003, 119:55-62.

59. APA: Diagnostic and Statistic Manual of Mental Disorders, 4th edition. Washington, DC: American Psychiatric Association; 1994

60. Caron J, Mercier C, Tempier R: Une validation québécoise du Satisfaction with Life Domains Scale. Sante Ment Que 1997, 22:195-218.

61. Fleury MJ, Grenier G, J.M B, Tremblay J: Typology of persons with severe mental disorders. BMC Psychiatry 2013, 13:137.

62. Cutrona C, Russell D, Rose J: Social support and adaptation to stress by the elderly. Psychol Aging 1986, 1:47-54.

63. Hendryx M, Dyck DG, McBride D, Whitbeck J: A test of the reliability and validity of the Multnomah Community Ability Scale. Community Ment Health J 2001, 37:157-168.

64. Bohn MJ, Babor TF, Kranzler HR: The Alcohol Use Disorders Identification Test (AUDIT): validation of a screening instrument for use in medial settings. J Stud Alcohol 1995, 56:423-432.

65. Accietto C: La validation d'une version française du questionnaire A.U.D.I.T. "Alcohol Use Identification Test". Université de Genève; 2003.

66. Cocco KM, Carey KB: Psychometric properties of the Drug Abuse Screening Test in Psychiatric Outpatients. Psychol Assessment 1998 10:408-414

67. Durbin J, Goering P, Streiner DL, Pink G: Continuity of care: Validation of a new self-report measure for individuals using mental health services. Journal of Behavioral Health Services \& Research 2004, 31:279-296.

68. Gravel R, Béland Y: The Canadian Community Health Survey: mental health and well-being. Can J Psychiatry 2005, 50:573-579. 69.

69. Barbato A, Monzani E, Schiavi T: Life satisfaction in a sample of outpatients with severe mental disorders: a survey in northern Italy. Qual Life Res 2004, 13:969-973.

70. Kovess-Masféty V, Xavier M, Moreno Kustner B, Suchocka A, Sevilla-Dedieu C, Dubuis J, Lacalmontie E, Pellet J, Roelandt J-L, Walsh D: Schizophrenia and quality of life: a one-year follow-up in four EU countries. BMC Psychiatry 2006, 6:39

71. Caron J, Corbière M, Mercier C, Diaz P, Ricard N: The construct validity of the client questionnaire of the Wisconsin Quality of Life index - a cross-validation study. Int J Methods Psychiatr Res 2003, 12:128-138.

72. Becker M, Diamond R, Sainfort F: A new patient focused index for measuring quality of life in persons with severe and persistent mental illness. Qual Life Res 1993, 2:239-251.

73. Caron J: Predictors of quality of life in economically disadvantaged populations in Montreal. Social Indicator Research 2012, 107:411-427.

74. Fleury MJ, Grenier G, Bamvita JM: Help received from relatives and services to satisfy needs of adults with severe mental disorders. Health 2013, 5:200-211.

75. Fleury MJ, Grenier G, Bamvita JM, Piat M, Tremblay J: Adequacy of help received among individuals with severe mental disorders. Administration and Policy in Mental Health 2013. Epub ahead of print.

76. Fleury MJ, Grenier G, JM B, Tremblay J: Factors associated with needs of users with severe mental disorders. Psychiatr Q 2012. Epub ahead of print

77. UK700Group: Predictors of quality of life in people with severe mental illness. Study methodology with baseline analysis in the UK700 trial. Br J Psychiatry 1999, 175:426-432.

78. Werner S: Subjective well-being, hope, and needs of individuals with serious mental illness. Psychiatry Res 2012, 196:214-219.

79. Bengtsson-Tops A, Hansson L: Clinical and social needs of schizophrenic outpatients living in the community: the relationship between needs and subjective quality of life. Soc Psychiatry Psychiatr Epidemiol 1999, 34:513-518

80. Landolt K, Rössler W, Burns T, Ajdacic-Gross V, Galderisi RS, Libiger J, Naber D, Derks EM, Kahn RS, Fleishchacker WW: The interrelation of needs and quality of life in first-episode schizophrenia. Eur Arch Psychiatry Clin Neurosci 2011, 262:207-216.

81. Slade M, Leese M, Taylor R, Thornicroft G: The association between needs and quality of life in an epidemiologically representative sample of people with psychosis. Acta Psychiatr Scand 1999, 100:149-157.

82. Hansson L, Sandlund M, Bengtsson-Tops A, Bjarnason O, Karlsson H, Mackeprang T, Merinder L, Nilsson L, Sorgaard K, Vinding H, Middelboe T: The relationship of needs and quality of life in persons with schizophrenia living in the community. A Nordic multi-center study. Nord J Psychiatry 2003, 57:5-11.
83. Caron J, Mercier C, Martin A, Stip E: Le rôle du soutien social, du fardeau familial et de la satisfaction des services dans la détresse psychologique et la qualité de vie des familles de personnes atteintes de schizophrénie. Sante Ment Que 2005, 30:165-191.

84. Langeland $E$, Wahl AK: The impact of social support on mental health service users' sense of coherence: A longitudinal panel survey. Int J Nurs Stud 2009, 46:830-837

85. Skantze K, Malm U, Dencker SJ, May PR, Corrigan P: Comparison of quality of life with standard of living in schizophrenic patients. Br J Psychiatry 1992, 161:797-801.

86. Priebe S: Social Outcomes in schizophrenia. Br J Psychiatry Supp/ 2007, 50:s15-s20.

87. Siegfried N: A review of comorbidity: major mental illness and problematic substance use. Aust N Z J Psychiatry 1998, 32:707-717.

88. Singh J, Mattoo SK, Sharan P, Basu D: Quality of life and its correlates in patients with dual diagnosis of bipolar affective disorder and substance dependence. Bipolar Disord 2005, 7:187-191.

89. Cedereke M, Ojehagen A: Patients' needs during the year after a suicide attempt. A secondary analysis of a randomised controlled intervention study. Soc Psychiatry Psychiatr Epidemiol 2002, 37:357-363.

90. Wennström E, Sörbom D, Wiesel FA: Factor Structure in the Camberwell Assessment of Need. Br J Psychiatry 2004, 185:505-510.

91. Fleury MJ, Piat M, Grenier G, Bamvita JM, Boyer R, Lesage A, Tremblay J: Components associated with adequacy of help for consumers with severe mental disorders. Administration and Policy in Mental Health and Mental Health Services Research 2010, 37:497-508.

92. Rüesch P, Graf J, Meyer PC, Rössler W, Hell D: Occupation, social support and quality of life in persons with schizophrenic or affective disorders. Soc Psychiatry Psychiatr Epidemiol 2004, 39:686-694.

doi:10.1186/1477-7525-11-92

Cite this article as: Fleury et al:: Predictors of quality of life in a

longitudinal study of users with severe mental disorders. Health and Quality of Life Outcomes 2013 11:92.

\section{Submit your next manuscript to BioMed Central and take full advantage of:}

- Convenient online submission

- Thorough peer review

- No space constraints or color figure charges

- Immediate publication on acceptance

- Inclusion in PubMed, CAS, Scopus and Google Scholar

- Research which is freely available for redistribution 